\title{
VARIAÇÃo DA LINHA DE COSTA E ASPECTOS socioeconômicos da Praia Brava, Matinhos-PR
}

\author{
Maria Carolina Stellfeld ${ }^{1 *}$, Everton Passos ${ }^{1}$
}

${ }^{1}$ Universidade Federal do Paraná, Pós-graduação em Geografia.

* Autor para correspondência: mcstellfeld@hotmail.com

Recebido em 17 de agosto de 2018. Aceito em 18 de dezembro de 2018. Publicado em 26 de dezembro de 2018.

\begin{abstract}
Resumo - O presente trabalho analisa características dos aspectos físicos e socioeconômicos da Praia Brava de Matinhos, município do litoral do estado do Paraná, com intuito de fornecer um diagnóstico para análise do risco à erosão costeira nesta praia. A avaliação do risco considerou as variáveis renda e população, valor das edificações a beira mar e sua distância até a linha de costa atual, além das taxas de variação desta linha, medidas em $\mathrm{m}$ /ano a partir de uma série temporal compreendendo o período de 1951 a 2016. As variáveis foram elegidas no contexto em que o risco é a probabilidade de um desastre acontecer, em função da vulnerabilidade física natural do ambiente praial de condições socioeconômicas da população exposta ao perigo e do valor de suas habitações, considerando sua resiliência frente a ameaça da erosão. Neste sentido os resultados da pesquisa evidenciam uma correlação entre valores negativos de variação da linha de costa e a desvalorização imobiliária, próximos à linha de costa.
\end{abstract}

Palavras-chave: Erosão costeira, anÁlise de risco, linha de costa, aspectos socioeconômicos.

\section{Shoreline variation and socioeconomic aspects of Praia Brava, Matinhos-PR}

AвSTRACT - The present work analyses physical and socioeconomic characteristics of the Brava Beach in Matinhos, a coastal municipality in the state of Paraná, with the purpose to provide a diagnosis of risk analysis on the coastal erosion in this particular beach. The risk assessment considered the variables income and population, property value in this area, and its respective distance to the actual shoreline, in addition to the variation rates of the shoreline that are measured in month/year from a time series comprising the period from 1951 to 2016. The variables were chosen in the context where the risk is the probability of a disaster to happen, due to the natural physical vulnerability of beaches, of the socioeconomic conditions of the population exposed to danger, and of the property values, considering its resilience to the threat of erosion. The results demonstrate a correlation between negative values of shoreline variation and real estate devaluation near the coastline.

KEYwORDS: COASTAL EROSION, RISK ANALYSIS, SHORELINE, SOCIOECONOMIC ASPECTS.

\section{Variación de la línea de costa y aspectos socioeconómicos de Praia Brava, Matinhos-PR}

RESUMEN - El presente trabajo analiza las características de los aspectos físicos y socioeconómicos de Praia Brava en Matinhos, municipio del litoral del Estado de Paraná, con el propósito de proporcionar un diagnóstico para el análisis del riesgo de erosión costera en esta playa. La evaluación del riesgo consideró las variables de renta y población, valor de las edificaciones a la orilla del mar y su distancia hasta la línea de costa actual, además de las tasas de variación de esta línea, medidas en $\mathrm{m} /$ año a partir de una serie temporal comprendiendo el período de 1951 a 2016. Las variables fueron elegidas en el contexto en que el riesgo es la probabilidad de que ocurra un desastre, en función de no sólo la vulnerabilidad física natural en el entorno de la playa de las condiciones socioeconómicas de la población expuesta al peligro, así como del valor de sus viviendas, 
considerando su resiliencia frente a la amenaza de la erosión. En este sentido los resultados de la investigación evidencian una correlación entre valores negativos de variación de la línea de costa y la devaluación inmobiliaria cercana a la línea de costa.

Palabras clave: Erosión costera, análisis de riesgo, línea de costa, aspectos socioeconómicos.

\section{INTRODUÇÃO}

A interface entre o ambiente continental e oceânico, onde "se faz sentir o efeito da maré" (Guerra e Guerra 1997), se destaca na configuração da paisagem do espaço geográfico, e é conhecida como zona costeira. No Brasil, a população dos municípios da zona costeira soma aproximadamente 50,7 milhões de habitantes, que representam $26,6 \%$ do total brasileiro (IBGE 2010). As zonas costeiras normalmente agregam qualidade de vida e crescimento econômico, resultado das atividades costeiras de produção do espaço, que estimulam a fixação de pessoas e o aumento de aglomerados urbanos (Reis, 2010).

Em paralelo à ocupação humana, na zona costeira o ambiente praial é o mais dinâmico. A morfodinâmica praial pode ser entendida como as interações entre os processos de formação e arrebentação das ondas e a resposta do leito frente a variações espaço-temporais, tornando-se mais complexa com forçantes naturais como maré, vento além das características sedimentares e biológicas (Short e Jackson 2013).

Deste modo, as ocupações litorâneas estão suscetíveis à morfogênese praial, que apresenta o fenômeno da erosão costeira e desastres associados como um dos principais problemas que surgem a partir da ocupação humana e da infraestrutura correlata neste espaço, transformando espaços construídos em áreas ameaçadas pela erosão. Identificar a erosão como um problema é um juízo de valor humano (Cooper 1998, 2007). O fenômeno da erosão pode causar grandes prejuízos, expondo ao perigo pessoas e bens, principalmente. Compreender os processos envolvidos na dinâmica costeira natural é fundamental para diminuir os efeitos deste dinamismo (Coelho 2005).

Desastre é um evento que obriga os habitantes de uma população a abandonar suas casas e ou lugares de trabalho, causando mortes, feridos e ou perdas de bens materiais ou produtivos, além de deteriorar a qualidade de vida da população ou por em perigo seu patrimônio (Wilches-Chaux 1998). O desastre não é o fenômeno em si, mas sim a consequência dos efeitos nocivos produzidos na população afetada.

Conceitualmente, ameaça é a probabilidade de ocorrer em determinado período e lugar, um evento seja de origem natural ou antrópica prejudicial para o homem (Alcantara-Carrió et al. 2009), e a sua extensão depende da susceptibilidade da área. Num fenômeno de magnitude determinada, o grau de perda ou dano produzido define a vulnerabilidade da área afetada (Varnes 1984). Alves (1997) define vulnerabilidade ambiental como a capacidade de resposta do ambiente numa situação de catástrofe, e a vulnerabilidade social é associada às pessoas que não dispõem de recursos financeiros e que ocupam áreas com pouca ou nenhuma infraestrutura ou recursos técnicos (Alves 2006; Braga et al. 2006).

A ocupação e produção do espaço geográfico pela sociedade faz parte dos geossistemas, sendo imprescindível à análise da condição social da população quando se visa a determinação do risco diante de uma ameaça. Autores como Cutter (2011), Braga (2006) e O’Riordan (2002), focam na resiliência da população como fator preponderante em relação a sua vulnerabilidade, numa relação direta entre população mais resiliente com menor vulnerabilidade. A resiliência aqui abordada se associa à capacidade de retorno da população a condições originais frente às perdas ocorridas pela erosão costeira, usando o conceito derivado da física que se refere à propriedade de alguns corpos em retornar ao estado original quando submetidos a esforços.

Deste modo, das definições apresentadas deriva o conceito de risco, que reflete a expectativa de perda de diferentes naturezas frente a uma ameaça. Também pode ser referido como probabilidade de ocorrência de processos no tempo e no espaço, não constantes e não-determinados, e a maneira como estes processos afetam, direta ou indiretamente, a vida humana (Castro et al. 2005). 
Neste trabalho o risco é considerado como o resultado da combinação entre o grau da ameaça, aqui representada pela erosão costeira, e a vulnerabilidade da população e da infraestrutura, representadas pelos indicadores socioeconômicos e os valores dos imóveis (Coelho 2005). Autores como Silva (2010) e Dagninino (2007) afirmam que discussões técnicas com diferentes abordagens do risco e suas conceituações são importantes para o desenvolvimento de modelos previsionais, assim se justifica a abordagem ora apresentada.

Assim, a pesquisa teve como objetivo analisar as variáveis consideradas indicadoras de áreas suscetíveis a desastres em relação à erosão costeira, considerando tanto fatores físicos quanto humanos, tendo como objeto para estudo de caso a Praia Brava.

\section{ОВjeto do eStudo de CASO}

A Praia Brava, banhada pelo Oceano Altântico, é localizada no município de Matinhos, litoral do Estado do Paraná, situando-se próxima ao delta que constitui a Baía de Guaratuba (Figura 1). Este município pertence a Mesorregião Metropolitana de Curitiba e Microrregião de Paranaguá e dista $111 \mathrm{~km}$ a sudeste da capital do estado, Curitiba. Com uma população 29.831 habitantes com densidade populacional de 254,96 habitantes por $\mathrm{km}^{2}$, estimada pelo Censo IBGE (2010), ocupa uma área de $117,064 \mathrm{~km}^{2}$, sendo que 4,75 $\mathrm{km}^{2}$ são áreas urbanas, densamente povoadas na orla municipal (1000 hab $/ \mathrm{km}^{2}$ aproximadamente). Neste trabalho o termo orla refere-se às faces de quadra de frente ao mar, ou ainda, a faixa de residência e infraestrutura que tem frentes voltadas para o mar.

Figura 1. Mapa de localização. Fonte: elaborado pela autora a partir de bases cartográficas do IBGE.

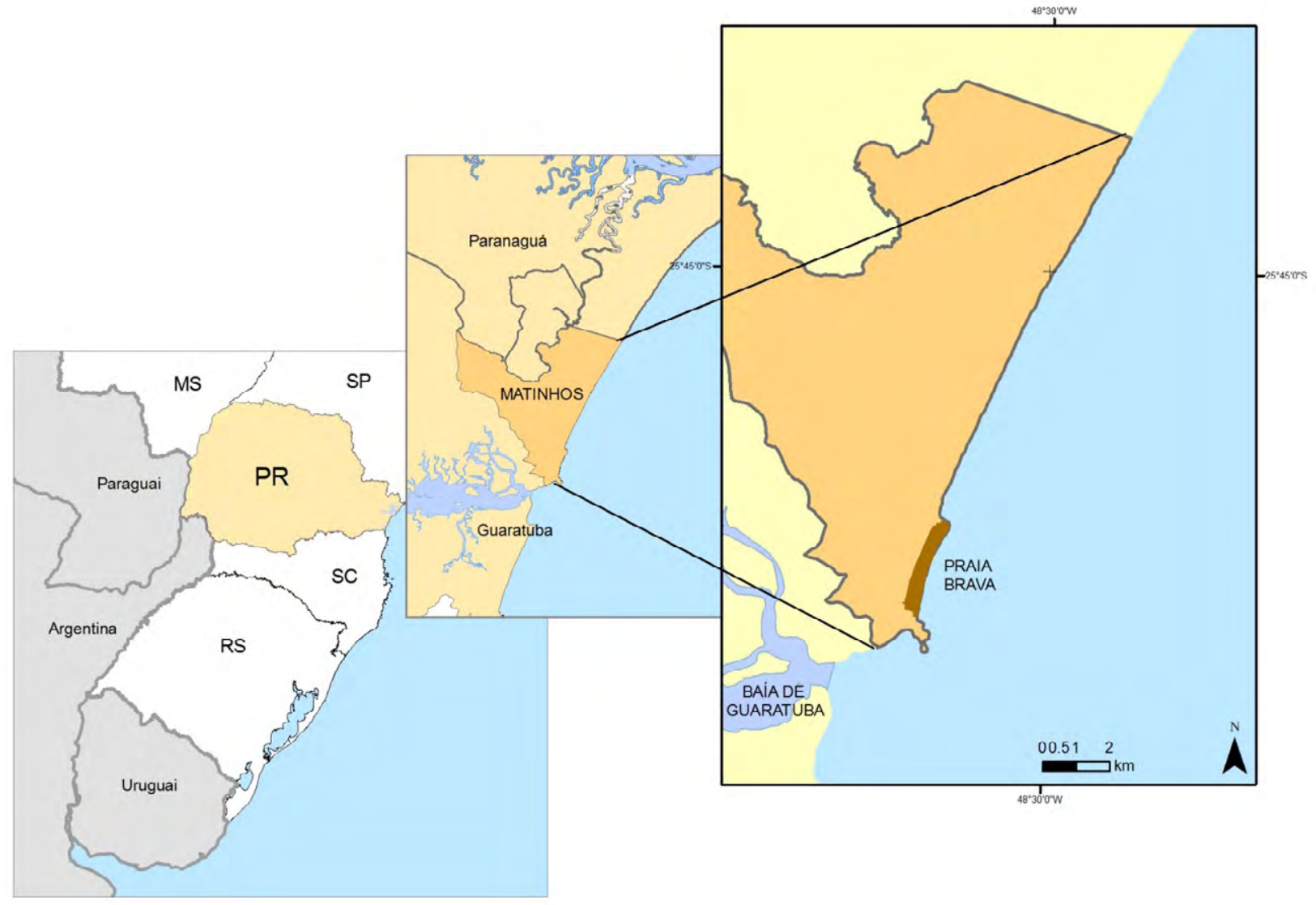

A Praia Brava é arenosa, com grãos finos, de micro-maré semi-diurnas com amplitudes máximas e mínimas ao redor de 2 e 0,5m (Soares et al. 1996), porém sem influência direta desta na morfodinâmica praial. A arrebentação de 
ondas observada é do tipo progressiva ou deslizante, que caracteriza-se por não movimentar uma grande quantidade de sedimentos e tem zona de surf bem marcada, gerando correntes tanto transversais como longitudinais.

Angulo (1993) descreve a influência dos deltas de maré vazante da baía de Guaratuba na sedimentação da Praia Brava, provocando refração de ondas e consequente corrente de deriva litorânea local. Apresenta característica de praia dissipativa, com variação para estágios intermediários registrados em meses de inverno. Processos de erosão e sedimentação sazonais estão presentes (Angulo e Araújo 1996), e estão condicionados a formação e destruição de barras submersas (Soares et al. 1996), onde situa-se a maior variabilidade morfológica desta praia.

O município de Matinhos teve diferentes movimentos na ocupação, desde os primórdios com ocupação indígena e portuguesa, migrando para vila no início do século 19, até 1950, quando foi construída a atual PR 407, impulsionando a ocupação da orla e as praias que começam a se consolidar como balneários (Bigarella 1991).

Deschamps et al. (2000) estudando a migração e aglomeração urbana dos municípios litorâneos paranaenses constataram um crescimento na aglomeração litorânea nas décadas de 1980 e 1990, pautado pela expansão e densificação da linha de costa por edifícios e parcelamentos de terrenos voltados ao uso sazonal de veranistas de média e alta renda, além da ocupação permanente que cresceu quase na mesma proporção. Junto ao aumento demográfico, também veio a valorização imobiliária de imóveis a beira-mar. Na década de 60 as casas da orla eram de moradores fixos, e atualmente a maioria dos imóveis a beira mar são de veraneio, com população flutuante. Em decorrência disso, houve valorização imobiliária e consequente ocupação por pessoas de alta renda.

Moura e Werneck (2000) comentam sobre a ocupação inadequada da orla paranaense, principalmente em áreas emersas resultantes da deposição natural da dinâmica costeira, que podem estar sujeitas a erosão costeira, situação evidente em episódios de ressaca. Angulo (1993) se referindo ocupação urbana do litoral ressalta o problema de ações antrópicas que invadiram o pós praia no município desencadeando processos erosivos na orla de Matinhos.

\section{Material e Métodos}

Na revisão bibliográfica se destacaram os elementos relacionados à abordagem sistêmica, analisando a paisagem atual por meio da compreensão de relações das dinâmicas naturais, reportadas a processos erosionais atuantes em faixa específica da zona costeira.

Do ponto de vista dos elementos físicos é notória a importância da mensuração da variação da linha de costa para entender o comportamento morfodinâmico de praias em relação à erosão costeira (Dias, et al. 1994; Linsde-Barros 2010; Boateng 2012; Chaaban et al. 2012; Souza 2016). A determinação da distância das edificações em relação à linha de costa atual complementa esta razão. A determinação correta da posição da linha de costa é função de diferentes definições e indicadores (Boak e Turner 2005). Neste trabalho o indicador escolhido é a linha de água máxima ou high water level (HWL) definido por diversos autores (Crowell, Leatherman e Buckley 1991; Leatherman 1983; Stafford e Langfelder 1971, in Boak e Turner 2005) como o limite úmido/seco da praia. Autores como Mazzer (2007), Barman et al. (2015), Rocha et al. (2010) e Marone et al. (2015) o utilizam este limite como referência da linha de costa, sendo que Moore (2006), Ruggiero et al. (2003) e Pajak e Leatherman (2002), corroboram a utilização deste indicador como adequado para a determinação da posição da linha de costa. Há controvérsias em relação ao uso deste indicador, principalmente no tocante ao posicionamento da linha em relação às diferenças de maré. Porém, trabalhos como os de Pajak e Leatherman (2002); Boak and Turner (2005), Moore et al. (2006) afirmam que este limite seco/úmido tem demonstrado ser o melhor indicador para a interface terra-água para estudos de comparação de linhas de costa em série histórica, pois é facilmente reconhecível no campo e pode ser identificada também em imagens de sensores remotos (Crowell et al. 1991), sendo que as possíveis diferenças no posicionamento deste limite dissipam-se ao longo período analisado (Pajak e Leatherman, 2002). Além disso, é mister lembrar que na latitude de Matinhos ocorrem micro-marés. 
O mapeamento da linha de costa também pode ser feito de diferentes maneiras, e trabalhos como os de Mazzer (2007), Chaaban et al. (2012) e Souza, (2016) usam imagens de sensores remotos como principal fonte de dados, principalmente quando se fala em uma análise multitemporal. A interpretação visual e o traçado manual em imagens de sensoriamento remoto é considerada como a técnica mais utilizada para extração das linhas de costa (Boak e Turner 2005; Chaaban et al. 2012), justifica este uso no presente trabalho sobre as imagens selecionadas. As feições morfológicas visíveis da Praia Brava, tais como bermas, foram importantes no posicionamento das linhas de costa definidas, marcando os limites entre a antepraia e a pós-praia, e praticamente coincidente com linha de água alta (HWL), utilizada como indicador de linha de costa nas imagens de sensores remotos (Boak e Turner, 2005 Pajak, M.J. e Leatherman 2002).

As imagens escolhidas para a extração das feições de linhas de costa atenderam os requisitos de disponibilidade por livre acesso público, boas condições de imageamento e recorte temporal satisfatório para determinar uma taxa de variação de linha de costa conforme parâmetros encontrados em Boak e Turner (2005) e Pajak e Leatherman (2002). Foram selecionadas fotografias aéreas dos anos de 1951 e 1980 e imagens de resolução espacial sub-métrica (<1m), dos anos de 2003, 2009 e 2016 disponíveis no Google Earth.

As imagens escolhidas foram mosaicadas conforme necessidade e georreferenciadas, para cada conjunto. Estas imagens serviram como base cartográfica para a extração das linhas de costa de cada ano. As linhas mapeadas resultaram da interpretação visual do indicador de linha de costa a WHL (Pajak e Leatherman 2002; Rocha et al. 2010; Marone et al. 2015), presente em todas as imagens e de fácil visualização, pois gera uma diferença de cor na areia, responsável pela diferença da praia seca e a praia úmida (Mazzer 2007). Além deste limite foi mapeada a linha do início da ocupação urbana por infraestruturas e imóveis edificados, usada para o cálculo das distâncias de edificações da linha de costa atual.

As linhas foram formatadas para os padrões do aplicativo Digital Shoreline Analises System (Thieler et al. 2009), que tem como objetivo calcular as distâncias entre linhas de costa que são cortadas por transectos paralelos à orla, equidistantes $100 \mathrm{~m}$ neste trabalho. Buscando evitar distorções nas médias calculadas foi realizada uma conferência nos transectos, tendo sido validados 32 transectos, excluindo aqueles que não cruzaram todas as linhas de costa. Também foi usado o valor RMS como um fator de incerteza do posicionamento das linhas de costa, conforme o ano. Deste processamento foram geradas as taxas de variação de linha de costa, expressa por m/a e a distância das edificações em relação à linha de costa de referencia do ano de 2016.

Seguindo os princípios anteriormente reportados de Cutter (2011), Braga (2006) e O’Riordan (2002), foram eleitas as variáveis que informam a renda e população (Bernatcheza 2011; Tominaga 2007; Cutter 2011; Cardona 2004; Braga 2006; Mendes et al. 2011), visando avaliar quantas pessoas estão expostas diretamente a ameaça da erosão costeira e qual sua condição financeira para se reestabelecer em caso de desastre provocado por esta ameaça. Estas variáveis foram derivadas de dados do Censo Demográfico Brasileiro (IBGE 2010), permitindo definir o cenário socioeconômico do espaço ocupado, com base na localização espacial dos setores censitários. Com objetivo de conseguir um resultado mais próximo à realidade dos dados censitários foi feita uma proporção entre área urbana total de cada setor e área representada pelas quadras do mar. O resultado foi um índice proporcional da área urbana situada na orla em relação ao total de área urbana de cada setor. $O$ índice serviu para estabelecer a mesma proporção nos valores da variável demográfica.

O valor financeiro das edificações da mesma maneira foi utilizado como variável socioeconômica, sendo usadas como referência as cifras da Planta Genérica de Valores Imobiliários, instrumento legal (Lei Municipal de Matinhos $\mathrm{N}^{\circ}$ 1266/2009) que determinam o valor das edificações por face de quadra dos municípios, para fins de tributação. Neste estudo de caso se utilizou as cifras das quadras defronte ao mar para fins de análise.

$\mathrm{Na}$ pesquisa foi priorizada a utilização de dados e informações que estão em domínio público, ou seja, todas as variáveis usadas são facilmente encontradas e passam por procedimentos simples de formatação. O livre acesso a informações democratiza a obtenção dos resultados e torna possível a replicação da metodologia em diferentes situações. 


\section{Resultados e Discussão}

\section{Taxa de Variação da Linha de Costa}

A média da taxa de variação da linha de costa encontrada na Praia Brava é de $-0,17 \mathrm{~m} /$ ano, indicando uma leve erosão, com tendência a estabilidade. O desvio padrão deste grupo é de 0,53 podendo ser interpretado como comportamento morfológico da própria praia que nitidamente apresenta duas situações distintas na análise temporal das linhas de costa. A maior taxa negativa de movimentação da linha de costa ficou em - $0,84 \mathrm{~m} /$ ano em um transecto no norte da praia e a maior taxa positiva foi de $0,68 \mathrm{~m} /$ ano em um transecto na porção centro sul da praia, corroborando a diferença no comportamento destes compartimentos (Figura 2).

Figura 2. Transectos classificados, por quebras naturais, usando a taxa de movimentação da linha de costa encontrada naquela direção.

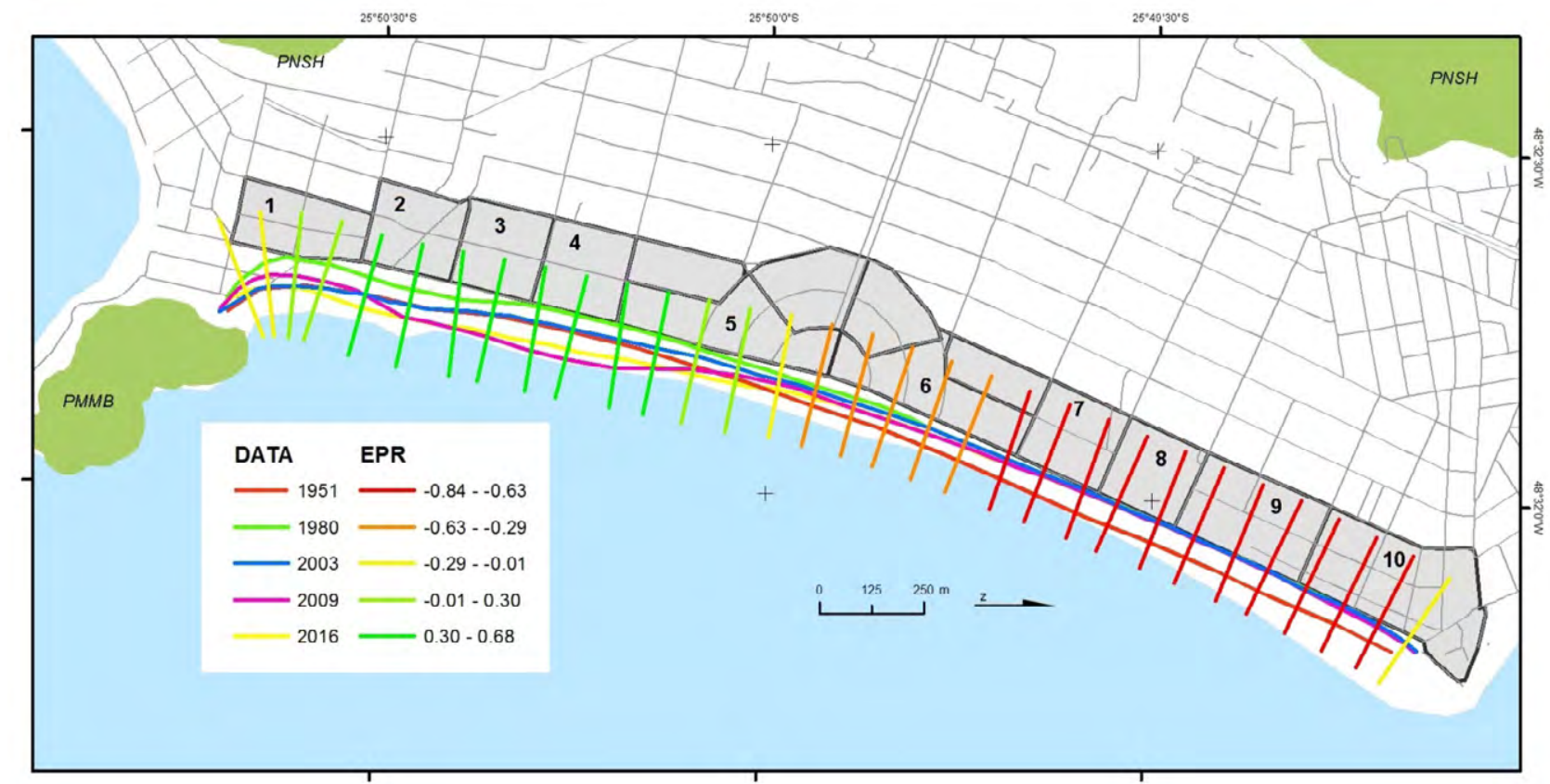

As taxas de variação da linha de costa negativas estão concentradas no trecho norte desta praia, corroborando com o histórico de destruição por erosão nestes locais, indicando erosão. Isto é uma tendência, pois este valor pode estar subestimado em função da estabilização da linha de costa por antropização, sendo que para aumentar a acurácia da medição de taxas deste trecho seriam necessárias análises do volume de areia.

Entretanto a simples comparação das imagens de satélite mais recentes é suficiente para se perceber que no trecho norte houve um processo de sedimentação. A comparação de imagens abaixo (Figura 3) mostra que no ano de 2001 os gabiões, usados como estruturas para impedir o avanço da erosão, eram bem aparentes. Já em 2012, na imagem os gabiões não são mais observados naquele local, evidenciando que estas estruturas foram cobertas por sedimentos arenosos da praia, mesmo não mudando a linha de costa local, como demonstra o mapeamento das linhas na série temporal. Assim, se evidencia que neste trecho os perfis de praia possibilitariam comprovar e calcular com mais acurácia as taxas de erosão. Indícios deste fenômeno existem como, por exemplo, a não fixação de vegetação na areia da praia e a linha de maré de sizígia muito próxima ao enrocamento de pedra que permanece exposto e fixa artificialmente a linha de costa. 
Figura 3. Comparação de trecho de praia. Observar os gabiões na primeira imagem, de 2001 e a falta dos mesmos em 2012, evidenciando o acúmulo de sedimentos neste trecho. Fonte: Intervenção da autora sobre imagens Google.

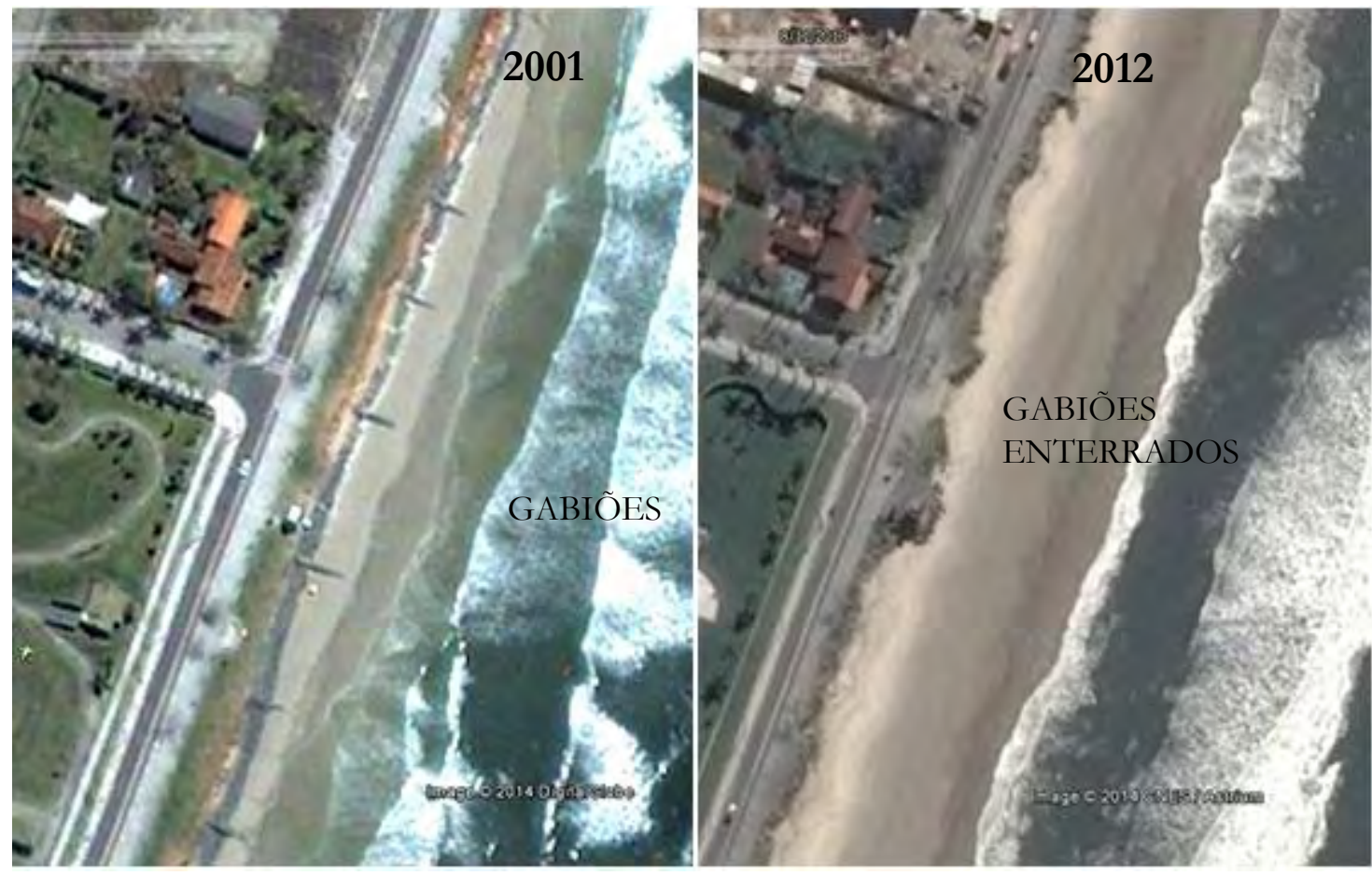

As taxas positivas estão concentradas na porção centro-sul desta praia, onde nitidamente é evidente uma acreção da praia nos últimos 16 anos, restaurando parte da restinga. Dois transectos na extremidade sul da Praia Brava apontam uma erosão leve, tendendo a estabilidade e podem ser fruto de condição morfológica pontual, com um balanço sedimentar diferente do regional e que não consegue ser discretizado com esta análise, conforme já alertado pelo algoritmo do DSAS para a rotina End Point Rate (EPR) (Thieler et al. 2009). A sedimentação da porção sul - que é atuante até hoje, se dá pela difração das ondas que é desviado pelo Morro do Boi (Angulo, 1993).

O expressivo resultado de 0,53 do desvio-padrão corrobora a visão já consagrada por Angulo (1993), de dois sistemas independentes para a Praia Brava, em função da diferença de ângulo que as ondas chegam nesta praia, oriundos da influência dos deltas de maré vazante da Baía de Guaratuba. Esta difração proporciona a sedimentação ao sul e pode ajudar a erosão na porção norte.

\section{Distância de Edificações}

A Praia Brava aparenta ter uma distribuição espacial proporcional das distâncias ao longo da orla, com distâncias maiores situadas a sul, e que vão diminuindo gradativamente para norte. $\mathrm{O}$ trecho ao sul é o que apresentava as maiores distâncias entre edificações e linha de costa no ano de 2016, com valor máximo de 136,37m (Figura 3). Ressalta-se que o extremo sul da praia tem uma acentuação no ângulo do arco praial, com algumas distâncias menores do que a média apresentada pela metade sul da praia, configurando uma exceção nesta distribuição. No trecho norte estão as menores distâncias medidas, com valor mínimo de $19 \mathrm{~m}$. Apesar da aparente distribuição normal destas distâncias, principalmente no posicionamento geográfico, $30 \%$ das medidas encontradas nesta praia são próximas ao valor mínimo, mostrando que o trecho norte tem um segmento mais crítico em relação à distância das edificações e a linha de costa. 
Figura 3. A) Trecho sul da Praia Brava, com destaque para o pós-praia extenso, corroborando com distância entre as edificações e a linha de costa neste trecho (foto autora janeiro/2018) e B) Gráfico com a frequência de distribuição das distâncias em metros na Praia Brava.

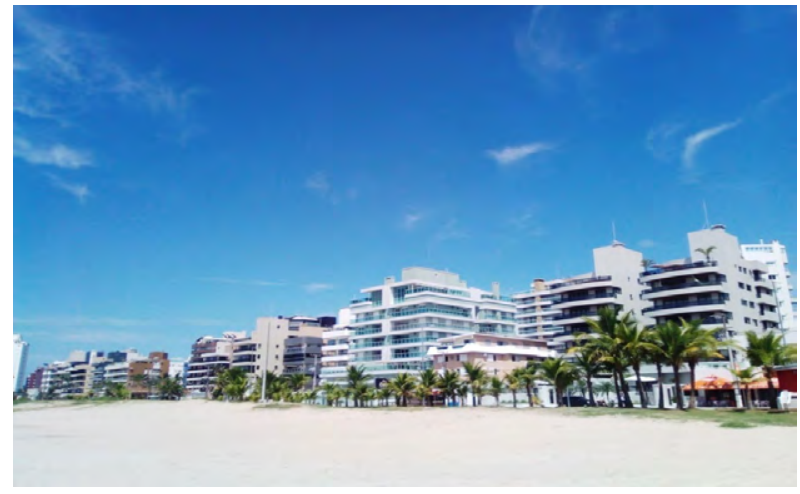

A

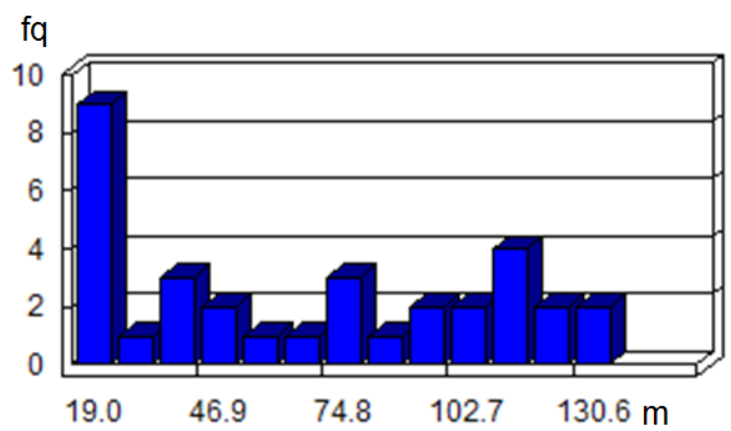

B

População e Renda

A população total calculada para a orla da Praia Brava é de 1212 pessoas, distribuídas em 14 setores censitários, sendo 10 limítrofes com o mar e os outros 4 com influência direta da orla. O setor mais populoso é o do extremo norte da praia com 214 pessoas, mostrando uma tendência de aglomeração próxima à área central da sede do município. Áreas próximas ao canal do DNOS e ao "centro" de Matinhos também concentram pessoas, porém com valor 50\% inferior no número de pessoas em relação ao setor mais populoso da praia. Nas áreas intermediárias a concentração populacional apresentou os menores valores de populacionais.

Em relação à renda, os setores censitários apontam valores entre $\mathrm{R} \$ 1196,39$ e $\mathrm{R} \$ 3863,79$. Espacialmente as maiores rendas se relacionam quase que diretamente com as áreas mais populosas, concentrando-se em três pontos principais - próximo ao centro de Matinhos e ao centro de Caiobá e nas proximidades do Canal DNOS. Em áreas intermediárias apresentam-se os menores valores de renda, sendo que na área centro-sul ocorrem os valores mais baixos da Praia Brava. A figura 4 mostra espacialmente os dados socioeconômicos analisados para a praia em questão, discretizados por setores censitários.

Figura 4. Setores censitários classificados por quebra natural, de acordo com a variável Renda e população para a Praia Brava.
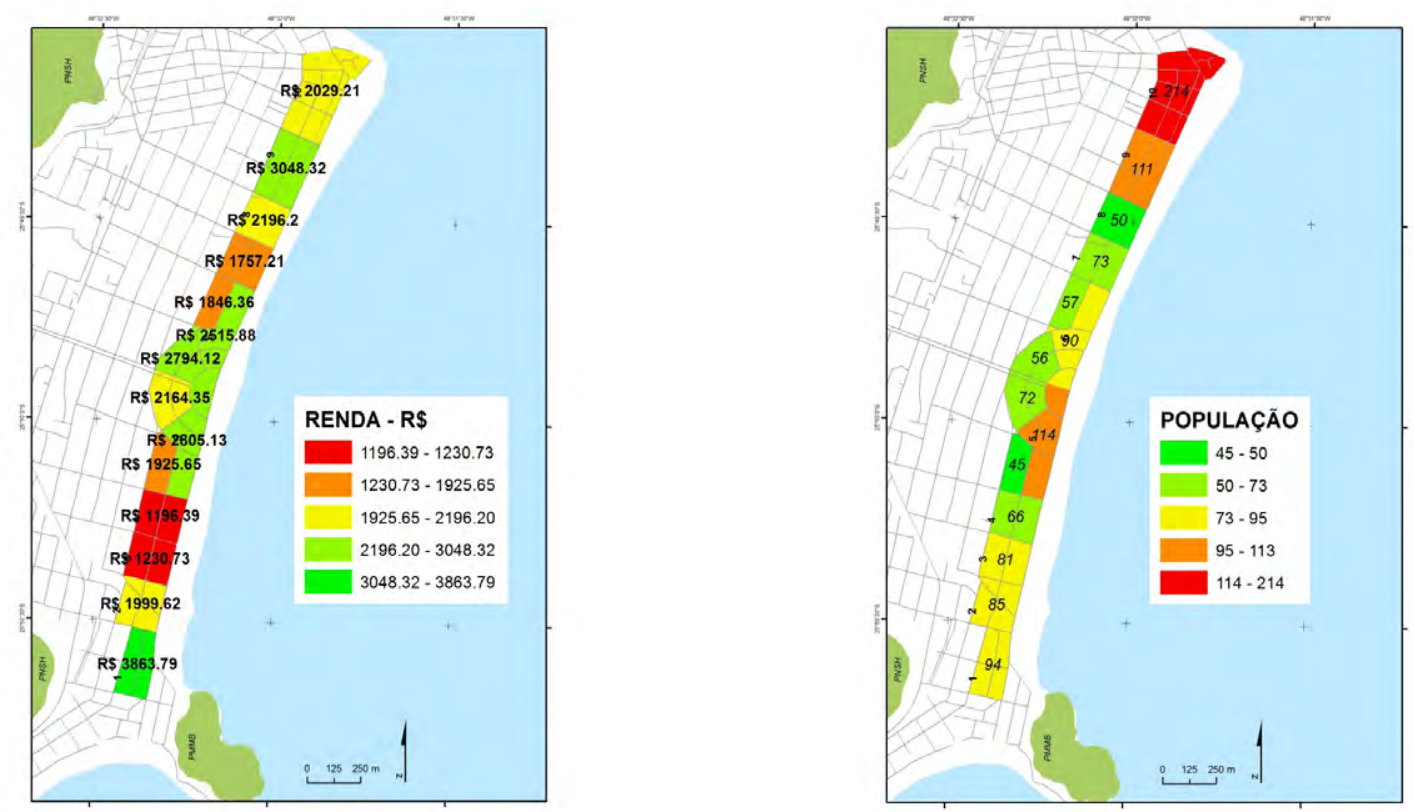
Planta Genérica de Valores Imobiliários (PGVI)

A Praia Brava apresenta 4 setores na PGVI, variando entre $\mathrm{R} \$ 700,00$ no extremo sul a $\mathrm{R} \$ 280,00$ no seu extremo norte (figura 5).

Figura 5. Valores em reais por $\mathrm{m} 2$ apontados na PGVI para a Praia Brava. Fonte: Elaborado pela autora

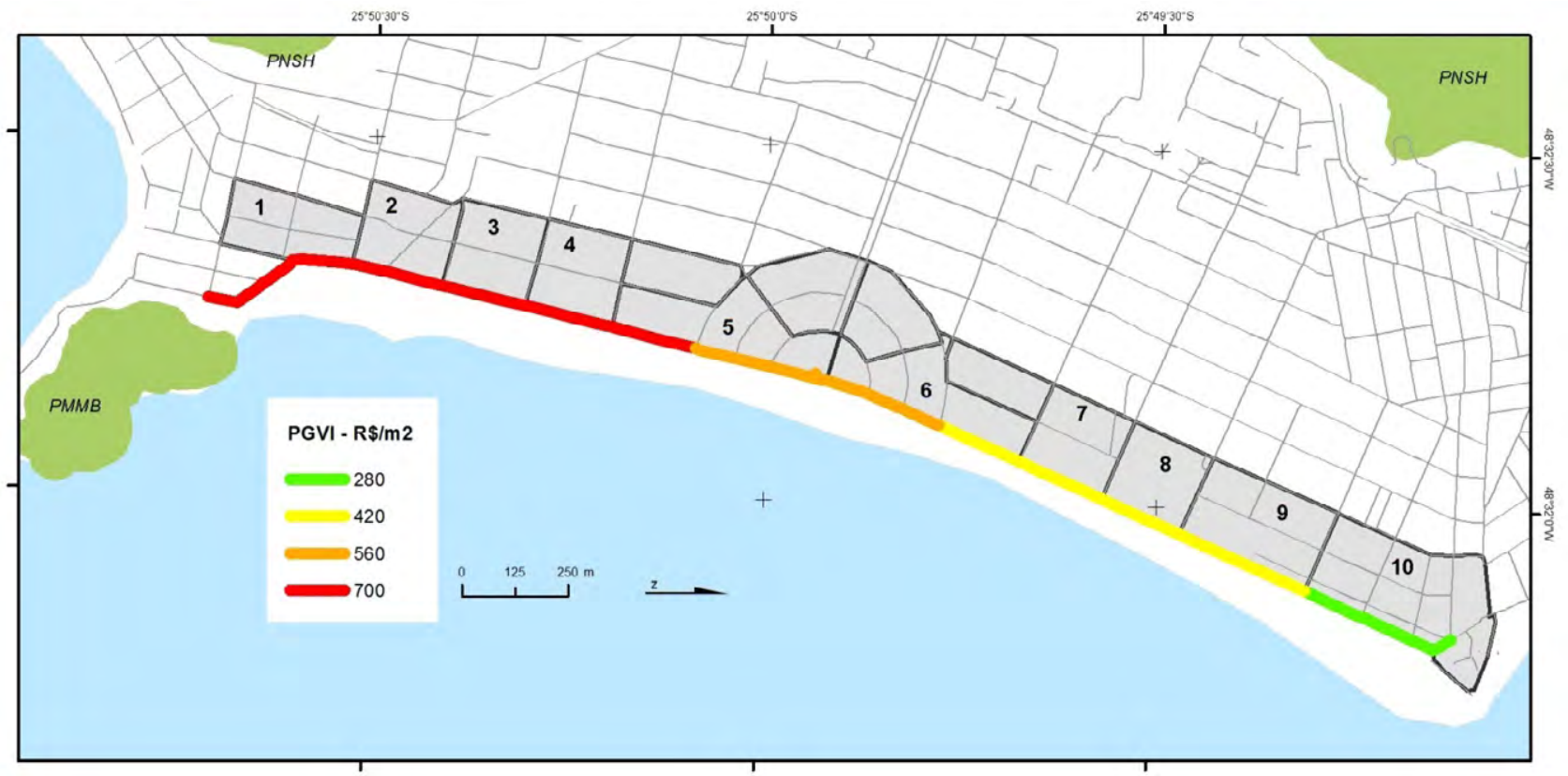

O trecho que tem valor de $\mathrm{R} \$ 700,00$ por $\mathrm{m}^{2}$ os edifícios de veraneio são predominantes coexistindo com imóveis comerciais do tipo restaurantes e pequenas lojas. No ano de 2017 o governo estadual realizou obras de revitalização desta orla, reformando calçadas, pista, ciclovia e instalando postes de iluminação e sinalização, canteiros e passeios como pode ser visto na fotografia da figura 6.

O segundo trecho, contíguo ao anterior avaliado em $\mathrm{R} \$ 560,00 \mathrm{o} \mathrm{m}^{2}$ corresponde às quadras centrais da praia, que apresentam formato semicircular, repartido pelo canal pluvial do DNOS. Apesar do valor indicado na PGVI ser o mesmo para ambos os lados do canal, localmente nota-se que somente o trecho sul teve a infraestrutura renovada em 2017, tendo o lado oposto condições de manutenção aparentemente menores, sem o mesmo padrão que as últimas obras de revitalização citadas (figura 6). Em relação às edificações ambos os trechos são semelhantes, com edifícios de até 10 pavimentos e poucas casas, predominando habitações de veraneio.

Figura 6. Aspectos da infraestrutura e edificações na Praia Brava, nos trechos avaliado em $\mathbf{R} \$ 700,00$ o m2 e 560,00 o $\mathrm{m} 2$, respectivamente. Fotografias da autora em janeiro/2018
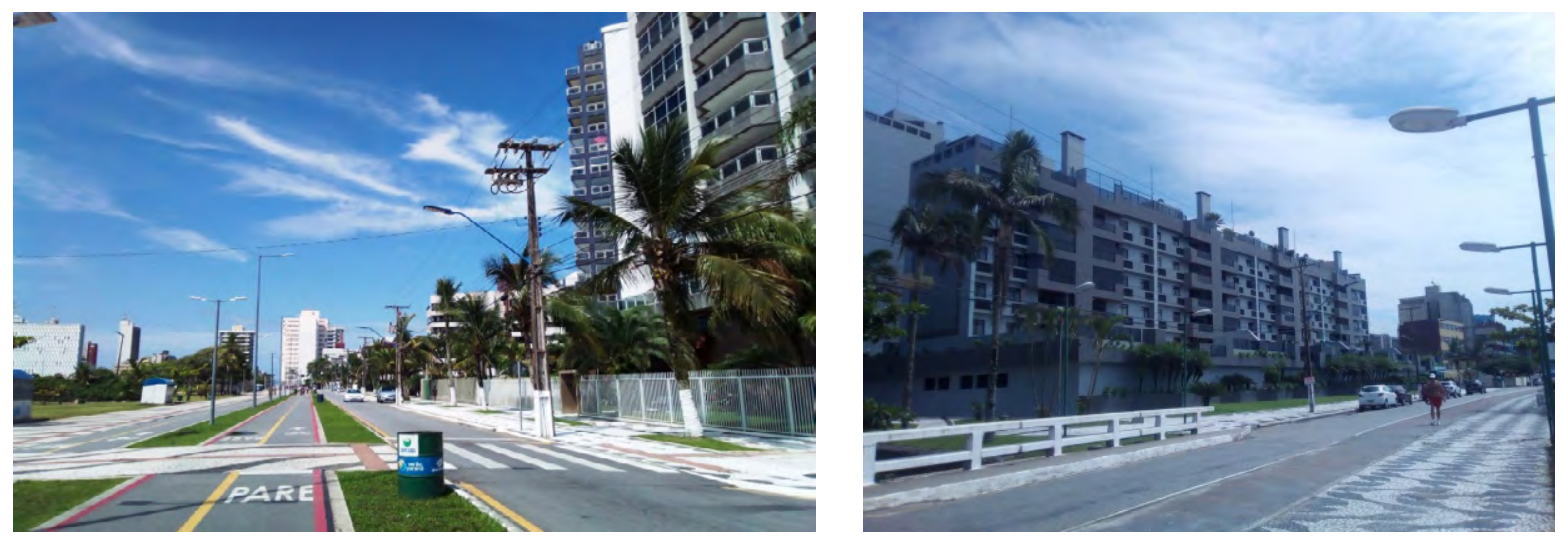
O terceiro trecho estende-se por aproximadamente $900 \mathrm{~m}$ e apresenta infraestrutura sem revitalização similar ao anterior, com cifras de $\mathrm{R} \$ 420,00 \mathrm{o} \mathrm{m}^{2}$. As edificações são parecidas às encontradas nos trechos anteriores, porém os edifícios são mais espaçados e as casas mais presentes. As calçadas podem apresentar pavimento solto e guias com sinalização falha, assim como a ciclovia existente não apresenta as faixas sinalizadas, denotando uma degradação da infraestrutura (figura 7).

O último trecho está no extremo norte da Praia Brava e tem valor de $\mathrm{R} \$ 280,00 \mathrm{o} \mathrm{m}^{2}$. Neste trecho o acesso à praia é difícil, com uma diferença de nivelamento da praia até o passeio de quase dois metros. As calçadas podem apresentar pavimento solto, as guias não estão completas e a ciclovia sem sinalização. As edificações de frente ao mar são mais esparsas e com fachadas menos conservadas, coexistindo com algumas lanchonetes, e com concentração de casas na parte interna das quadras (figura 7).

Figura 7. Aspecto dos trechos da Praia Brava, com edificações avaliados em $\mathbf{R} \$ 420,00$ o $\mathrm{m} 2$ e $\mathbf{R} \$ 280,00$ o m2, respectivamente.
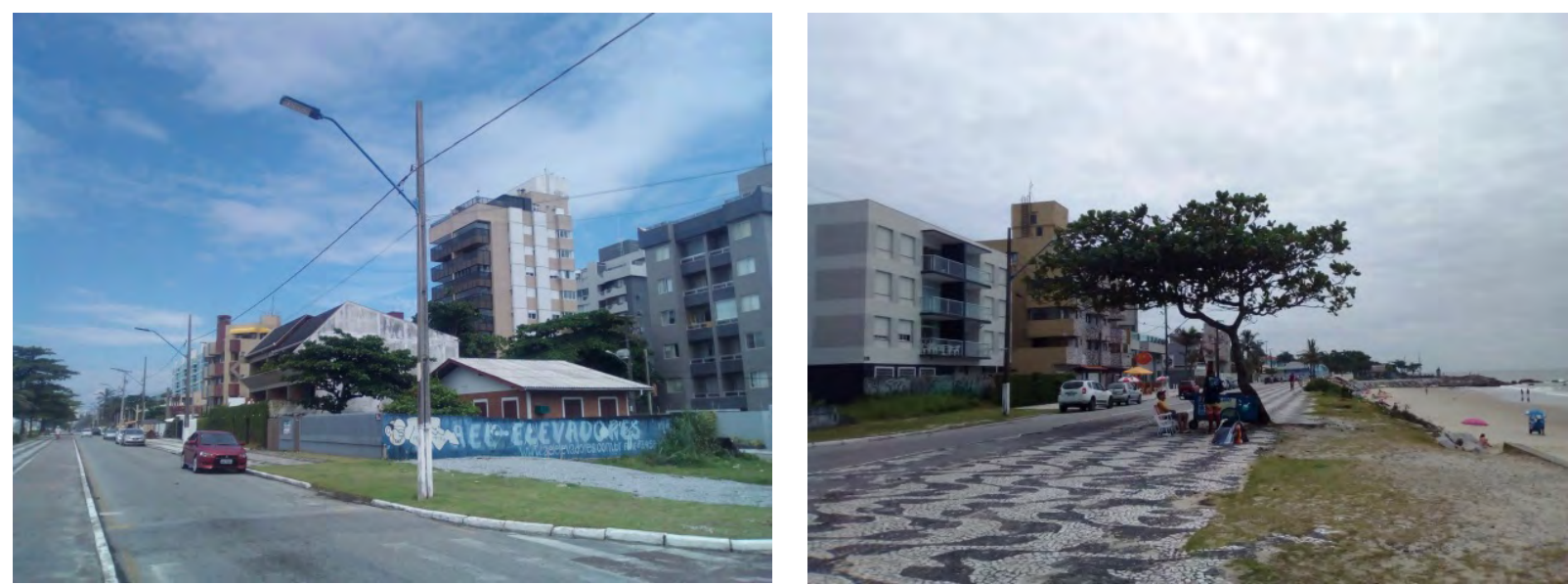

Sintese do grau de influência das variáveis

O quadro 1 resume a influência, numa graduação entre a negativa - escuro, e a positiva - clara, para cada variável em relação ao setor censitário limítrofe da orla. Na sequência, o setor censitário de número 1 é o mais ao sul da praia e o último setor, o mais ao norte. Para as variáveis renda e distância da linha de costa, quanto maior valor, menor o risco em relação à erosão costeira. Já para as variáveis PGVI, população, taxa de variação de linha de costa, quanto maior valor, maior o risco associado.

Quadro 1. Matriz de correlação entre variáveis e setores censitários, numa graduação de tons sendo os escuros indicando influência negativa e os claros indicando influência positiva.

\begin{tabular}{|l|l|l|l|l|l|l|l|l|l|l|}
\hline \multicolumn{1}{|c|}{ Variável/Setor } & 1 & 2 & 3 & 4 & 5 & 6 & 7 & 8 & 9 & 10 \\
\hline População & & & & & & & & & & \\
\hline Renda & & & & & & & & & & \\
\hline PGVI & & & & & & & & & & \\
\hline LC m/a & & & & & & & & & & \\
\hline Distância LC & & & & & & & & & & \\
\hline
\end{tabular}




\section{ConClusões}

É reconhecida a relação entre aspectos físicos e sociais das vulnerabilidades, sendo que a vulnerabilidade ambiental depende do posicionamento geográfico e das condições ambientais do fenômeno analisado e a vulnerabilidade social indica a capacidade relativa individual para responder a este fenômeno. Em consonância com Santos e Ventorini (2017), os dados aqui apresentados constituem uma tentativa simplificada de mapear e analisar áreas ameaçadas por eventos naturais e a relação com a população que habita este espaço, visto que estes dependem de um recorte espaço-temporal, combinando uma realidade dinâmica e a disposição heterogênea dos fenômenos.

A ferramenta de Sistemas de Informações Geográficas mostrou-se eficiente para uma análise holística de variáveis, tanto sociais como físicas, oferecendo vantagens por padronizar e integrar as variáveis escolhidas, além de permitir a espacialização destas informações no espaço geográfico analisado. O processamento dos dados com o aplicativo DSAS demonstra que é possível obter dados quantitativos sobre erosão de praias, ao longo do tempo, de maneira eficiente.

Os dados da Praia Brava mostram que há uma relação direta entre distância das edificações em relação a linha do ano de 2016 e taxa de variação da linha de costa com tendência erosiva, sendo que os valores mais intensos para ambas variáveis estão localizados na porção norte da praia. No norte da praia também está a maior quantidade de pessoas por setor censitário desta praia, provavelmente devida à proximidade do centro da sede do município de Matinhos.

Os dados mapeados demonstram bem a localização espacial da população residente e sua condição financeira. Um fator interessante notado neste sentido é encontrado no trecho centro sul da Praia Brava, onde estão localizados os imóveis mais valorizados e a população com a menor renda média da praia. Esta relação pode ter origem na profissão de zeladores/caseiros dos apartamentos de média-alta classe, numa situação onde normalmente estes trabalhadores residem nos próprios locais de trabalho, sem necessariamente ter a propriedade destes imóveis. É possível também perceber uma relação quase direta entre imóveis mais valorizados e menor população, indicando uma provável maioria de residências de veraneio. $\mathrm{O}$ trecho centro sul também é a área com as maiores distâncias das edificações em relação à linha de costa atual, além de uma taxa positiva de variação de linha de costa. Assim, mesmo que os imóveis apresentem alto valor imobiliário, o que significa ter razoável disposição financeira para ser resiliente em caso de desastre, a condição natural indica uma baixa vulnerabilidade ambiental neste trecho.

Os dois setores mais setentrionais da Praia Brava são os mais críticos em relação à exposição ao risco de erosão costeira, por apresentarem a maior concentração de pessoas, $33 \%$ da população da orla da Praia Brava, com renda per capita equivalente a metade da maior renda do trecho analisado, e com imóveis mais próximos da linha de costa atual, mostrando distâncias 7 vezes menores que na porção sul. Em contrapartida, os imóveis localizados nestes setores são pouco valorizados, apresentando cifras de PGVI 60\% menores que os imóveis localizados na parte sul da Praia Brava, indicando uma possível resiliência financeira frente aos desastres que possam ocorrer. Aliado a estas condições, as taxas de variação de linha de costa negativa são as mais altas da praia, quase 3 vezes maior do que as taxas negativas encontradas na porção central do arco praial.

Estas conclusões podem fazer refletir sobre como estão sendo alocados os recursos da manutenção da orla. Atualmente a porção sul da Praia Brava é que tem a manutenção de estruturas mais bem cuidada, onde há uma valorização dos imóveis, como provável consequência do investimento público, mesmo não sendo o local onde vive a maioria da população da Praia Brava, tão pouco ocorre elevadas taxas de erosão. Do outro lado, onde os processos físicos estão mais intensos, aparentemente o desinteresse imobiliário, talvez resultante do próprio fenômeno da erosão, não incrementa a atuação do poder público na manutenção deste trecho da orla, ou ainda na solução efetiva do problema. As informações aqui apresentadas visam servir aos gestores como referência para tomada de decisão na prevenção de riscos à ocupação e uso deste reduzido espaço geográfico, de relevância socioeconômica por centralizar inúmeras atividades humanas na região. É conhecido que os índices disponíveis atualmente nem 
sempre mostram completamente a vulnerabilidade dos geossistemas e todas as interações complexas. Mesmo assim, o esforço para refinar variáveis que as descrevam e as possibilidade de serem integradas, podem e devem ser incentivados e aperfeiçoados.

Finalmente pode se afirmar que a metodologia proposta para o estudo foi bastante satisfatória e a sua aplicação em outras praias pode servir para uma melhor avaliação da sua eficiência.

\section{Agradecimentos}

Os autores agradecem a Capes, ao Programa de Pós-graduação em Geografia da UFPR e ao Laboratório de Geoprocessamento e Estudos Ambientais.

\section{REFERÊNCIAS}

Alcántara Carrió J. Correa Arango ID, Isla De Medy FI, Alvarado MO, Klein AHF, Cabrera Hernández A, Sandoval RB (Eds). 2009. Métodos En Teledetección Aplicada A La Prevención De Riesgos Naturales En E1 Litoral. Servicio De Publicaciones Del Programa Iberoamericano De Ciencia Y Tecnología Para El Desarrollo. Madrid, Espanha. 297 p.

Alves F, Taveira Pinto F, Ferreira JC. 1997. A Análise Da Vulnerabilidade E Do Risco Na Zona Costeira Como Contributo Para A Tomada De Decisão. III Congresso Da Geografia Portuguesa, Porto - Portugal. Edições Colibri, Lisboa 1999. p. 559-556.

Alves HPF. 2006. Vulnerabilidade socioambiental na metrópole paulistana: uma análise sociodemográfica das situações de sobreposição espacial de problemas e riscos sociais e ambientais. R. bras. Est. Pop. São Paulo. 23(1):43-59.

Angulo RJ. 1993. A ocupação urbana do litoral paranaense e as variações da linha de costa. Boletim Paranaense de Geociências, Curitiba, 41:73-81.

Angulo RJ, Araújo AD. 1996. Classificação da Costa Paranaense com base na sua Dinâmica, como Subsídio à Ocupação da Orla Litorânea. Boletim Paranaense de Geociências. 44:7-17.

Barman NB, Chatterjee, S, Khan A. 2015. Trends of Shoreline Position: An Approach to Future Prediction for Balasore Shoreline, Odisha, India. Open Journal of Marine Science, 5:13-25.

Bernatcheza P, Fraserb C, Lefaivrec D, Dugasb S. 2011. Integrating anthropogenic factors, geomorphological indicators and local knowledge in the analysis of coastal flooding and erosion hazards. Ocean e Coastal Management.54(8): 621-632.

Bigarella JJ. 1991. Matinho: Homem e terra Reminiscências... Matinhos. Pref. Mun. Matinhos/ADEA. 212p.

Boak EH e Turner IL. 2005. Shoreline definition and detection: A review. Journal of Coastal Research. 214:688-703.

Boateng I, 2012. An application of GIS and coastal geomorphology for large scale assessment of coastal erosion and management: a case study of Ghana. Journal of Coastal Conservation Planning and Management 16:(3)383-397.

Braga TM, Oliveira EL de, Givisiez GHN. 2006. Avaliação de metodologias de mensuração de risco e vulnerabilidade social a desastres naturais associados à mudança climática. São Paulo em Perspectiva. Fund. SEADE. 20(1):81-95. 
Cardona OD. 2004. The need for rethinking the concepts of vulnerability and risk from a holistic perspective: a necessary review and criticism for effective risk management. In: Bankoff G, Frerks G, Hilhorst D. (Eds.). Mapping vulnerability: disasters, development, and people. London: Earthscan Publications, p. 37-51.

Castro CM de, Peixoto MNO, Pires Do Rio GA. 2005. Riscos Ambientais E Geografia: Conceituações, Abordagens E Escalas. Anuário Do Instituto De Geociências - Ufrj Issn 0101-9759. 28(2):11-30

Chaaban F, Darwishe H, Battiau-QueneyY, Louche B, Masson E, El Khattabi J, Carlier E. 2012. Using ArcGIS® Modelbuilder and Aerial Photographs to Measure Coastline Retreat and Advance: North of France. Journal of Coastal Research: 28(6):1567-1579.

Coelho C. 2005. Riscos De Exposição De Frentes Urbanas Para Diferentes Intervenções De Defesa Costeira. Tese De Doutorado. Departamento De Engenharia Civil. Universidade De Aveiro. 404 p.

Cooper JAG, Mclaughin S. 1998. Contemporary Multidisciplinary Approches To Coastal Classification And Environmental Risks Analysis. Journal Of Coastal Research 14 (2): 512-524.

Cooper JAG, McKenna J. 2007. Social justice in coastal erosion management: The temporal and spatial dimensions. Geoforum - Elsiever. 39:294-306.

Crowell M, Leatherman SP, Buckley MK. 1991. Historical Shoreline Change: Error Analysis And Mapping Accuracy. Journal of Coastal Research 7(3):839-852.

Cutter SL. 2011. A ciência da vulnerabilidade: modelos, métodos e indicadores. Revista Crítica de Ciências Sociais, ed especial Riscos, Vulnerabilidade Social e cidadania. 93:59-69.

Dagnino RS, Carpi Jr S. 2007. Risco Ambiental: Conceitos e Aplicações. Climatologia e estudos da Paisagem. Rio Claro. 2:50.

Deschamps MV, Kleinke MLU, Moura R, Werneck DZ. 2000. Afinal, O Que Induz O Crescimento Nas Aglomerações Litorâneas? In: Anais do XII Encontro Abep. Caxambu. Abep.Cd.

Dias JA, Ferreira O, Pereira AR. 1994. Estudo Sintético de Diagnóstico da Geomorfologia e da Dinâmica Sedimentar dos Troços Costeiros entre Espinho e Nazaré. Relatório Final Interno. Instituto da Conservação da Natureza, Lisboa. 137p.

Guerra AT, Guerra AJT. 1997. Novo Dicionário Geológico-Geomorfológico. Rio de Janeiro: Bertrand Brasil. 642 p.

Hoefel FG. 1998. Morfodinâmica De Praias Arenosas Oceânicas: Uma Revisão Bibliográfica. Universidade Do Vale Do Itajaí. $1^{a}$ Edição. Editora Da Univali. Itajaí, Sc. 92p.

INSTITUTO BRASILEIRO DE GEOGRAFIA E ESTATÍSTICA (IBGE). Censo Demográfico 2010: Manual do Recenseador - CD 1.09. Rio de Janeiro: IBGE, 2010.

Leatherman SP. 1983. Historical and projected shoreline mapping. Proceedings of the Coastal Zone '83. San Diego, California, pp. 2902-2910.

Lins-de-Barros FM. 2010. Contribuição metodológica para análise local da vulnerabilidade costeira e riscos associados: estudo de caso da Região dos Lagos, Rio de Janeiro. Tese de Doutorado, Pós-Graduação em Geografia. UFRJ. 289p. 
Marone E, Castro Carneiro J, Cintra M, Ribeiro A, Cardoso D, Stellfeld MC. 2015. Extreme sea level events, coastal risks, and climate changes: informing the players. In: Wyss M, Peppoloni S (Eds.), Geoethics: Ethical Challenges and Case Studies in Earth Science. Elsevier, Waltham, Massachusetts, pp. 273-302.

Mazzer AM. 2007. Proposta Metodológica De Análise De Vulnerabilidade Da Orla Marítima À Erosão Costeira: Aplicação Na Costa Sudeste Da Ilha De Santa Catarina, Florianópolis-Sc, Brasil. Tese De Doutorado. Programa De Pós Graduação Em Geociências, Universidade Federal Do Rio Grande Do Sul, 169 p.

Mendes JM, Tavares AO, Cunha L, Freiria S. 2011. A vulnerabilidade social aos perigos naturais e tecnológicos em Portugal. Revista Crítica de Ciências Sociais. 93:95-128.

Moore JL, Ruggiero P, List JH. 2006. Comparing Mean High Water and High Water Line Shorelines: Should Proxy-Datum Offsets be Incorporated into Shoreline Change Analysis? Journal of Coastal Research: 22(4): 894 - 905.

Moura R, Werneck DK. 2000. Ocupação contínua litorânea do Paraná: uma leitura do espaço. Revista Paranaense de Desenvolvimento, Curitiba: IPARDES, 99:61-82.

O’Riordan T. 2002. Precautionary Principle. in: Tolba MK. (Ed.). Encyclodia of Global Environmental Change. Ed.John Wiley Chichester, UK. v. 4.

Pajak MJ e Leatherman S. 2002. The high water line as shoreline indicator. Journal of Coastal Research, 18(2):329-337.

Reis MEO. 2010. Evolução Da Linha De Costa E Defesa Das Zonas Costeira - Análise Custo/Benefício. Dissertação De Mestrado. Departamento De Engenharia Civil. Universidade De Aveiro, 105p.

Rocha CP, Araújo TCM, Mendonça FJB. 2010. Monitoramento De Linha De Costa Usando Posicionamento 3d-Gps. III Simpósio Brasileiro de Ciências Geodésicas e Tecnologias da Geoinformação Recife - PE, 27-30 de Julho de 2010 p. $001-008$.

Ruggiero P, Kaminsky GM, Gelfenbaum G. 2003. Linking Proxy-Based and Datum-Based Shorelines on a High-Energy Coastline: Implications for Shoreline Change Analyses. Journal of Coastal Research. Special Issue no. 38. Shoreline Mapping and Change Analysis: Technical Considerations and Management Implications. pp. 57-82.

Santos TG, Ventorini SE. 2017. Análise Multicritério: modelos de interesse ambiental e de áreas propícias à expansão urbana na bacia do córrego do Lenheiro. Caminhos da Geografia, Uberlândia, MG. 18(64):60-77.

Soares C R, Borzone CA, Souza JRB. 1996 . Variações morfológicas e sedimentológicas ao longo de um ciclo anual em uma praia no sul do Brasil. Oecologia Brasiliensis, Rio de Janeiro, III:245-258.

Short AD e Jackson DWT. 2013. Beach Morphodynamics. In: John F. Shroder (ed.) Treatise on Geomorphology. San Diego: Academic Press. Volume 10, pp. 106-129.

Silva RCAF. 2010. Avaliação experimental e Numérica de parâmetros associados a modelos de evolução da linha de costa. Tese de Doutorado, Faculdade de Engenharia, Universidade do Porto. Portugal. 544p.

Souza WF. 2016. Sensoriamento remoto e SIG aplicados à análise da evolução espaço-temporal da linha de costa do município de Icapuí, Ceará - Brasil. Dissertação de mestrado, Pós-graduação em Geografia, UFC. 135p. 
Thieler ER, Himmelstoss EA, Zichichi JL, Ergul A, 2009. Digital Shoreline Analysis System (DSAS) version 4.0 - An ArcGIS extension for calculating shoreline change: U.S. Geological Survey Open-File Report 2008-1278.

Tominaga L K. 2007. Avaliação de metodologias de análise de risco a escorregamentos: aplicação de um ensaio em Ubatuba, SP. Tese de Doutorado, Faculdade de Filosofia, Letras e Ciências Humanas, USP, 220p.

Varnes DJ. 1984. Landslide hazard zonation: a review of principles and practice. International Association of Engineering Geology. Commission on Landslides and Other Mass Movements on Slopes. United Nations Educational, Scientific and Cultural Organization. Paris, France. 63p.

Wilches - Chaux G. 1998. Auge, caída y levantada de Felipe Pinillo, mecánico y soldador o yo voy a correr el riesgo : Guía de La Red para la gestión local del riesgo. Red de Estudios Sociales en Prevención de Desastres en América Latina (La Red); 1998. 103 p. 